\title{
Root-Knot Nematode Resistance in Pearl Millet From West and East Africa
}

\author{
P. Timper and J. P. Wilson, United States Department of Agriculture-Agricultural Research Service (USDA-ARS) \\ Crop Protection and Management Research Unit, and USDA-ARS Crop Genetics and Breeding Research Unit, Tif- \\ ton, GA 31793-0748
}

\begin{abstract}
Timper, P., and Wilson, J. P. 2006. Root-knot nematode resistance in pearl millet from West and East Africa. Plant Dis. 90:339-344.

Resistance to Meloidogyne incognita is important to provide stability to pearl millet production and to reduce nematode populations that can damage crops grown in rotation with pearl millet. The objectives of this study were to determine whether resistance to M. incognita exists in pearl millet from West and East Africa, and to determine if heterogeneity for resistance exists within selected cultivars. Resistance was assessed as nematode egg production per gram of root in greenhouse trials. Seventeen pearl millet cultivars of diverse origin were evaluated as bulk $\left(\mathbf{S}_{0}\right)$ populations. All African cultivars expressed some level of resistance. P3Kollo was among the least resistant of the African cultivars, Zongo and Gwagwa were intermediate, and SoSat-C88 was among the most resistant. Thirty selfed $\left(S_{1}\right)$ progeny selections from SoSat-C88, Gwagwa, Zongo, and P3Kollo were evaluated for heterogeneity of resistance within cultivar. Reactions were verified in $13 \mathrm{~S}_{2}$ progeny of each of the four cultivars. In $S_{1}$ evaluations, each of these cultivars was heterogeneous for resistance. Progeny reaction varied from highly resistant to highly susceptible. Patterns of apparent segregation of resistance varied among the four cultivars. Discreet resistant and susceptible phenotypes were identified in Zongo progeny, and it was estimated that two dominant genes for resistance segregated in this cultivar. Averaged across progenies, egg production on the four cultivars was less $(P \leq 0.001)$ than on the susceptible hybrid HGM-100, but was not different from resistant hybrid TifGrain 102. Reproduction of M. incognita on the $S_{2}$ progeny tended to confirm the results from inoculations of $S_{1}$ progeny. Heritability of nematode reproduction (standardized as the ratio of the value to HGM-100) determined by parent-offspring regression was 0.54 . Realized heritability determined by divergent selection was 0.87 .
\end{abstract}

Additional keywords: Southern root-knot nematode

Sub-Saharan Africa is the primary center of diversity for pearl millet (Pennisetum glaucum (L.) R. Br.). Cultivars throughout this region are maintained as openpollinated cultivars ranging from traditional landraces, which are relatively unimproved and sometimes contaminated by cross-pollination with wild relatives, to improved cultivars maintained in a relatively pure state. Consistent with its crosspollinating reproductive behavior, pearl millet lines from West and East Africa are genetically heterogeneous. Germ plasm from this region has the potential to be sources of resistance to diseases and pests for crop improvement programs (16-18).

In the United States, pearl millet is grown primarily in the southern region, where nematodes are important constraints in cropping systems. Meloidogyne spp. are

Corresponding author: P. Timper

E-mail address: ptimper@tifton.usda.gov

Accepted for publication 13 October 2005.

DOI: 10.1094/PD-90-0339

This article is in the public domain and not copyrightable. It may be freely reprinted with customary crediting of the source. The American Phytopathological Society, 2006. the most economically important plantparasitic nematodes in the southern United States as well as in West Africa, with Meloidogyne incognita being the dominant species in both regions $(2,11,12)$. Pearl millet is a known host for M. incognita (68 ), but the importance of the nematode in African production settings is not clear. If $M$. incognita is not a yield constraint for pearl millet in African production, resistance would be a selectively neutral trait and there should be little reason for high levels of resistance to be maintained in pearl millet from Africa. However, if nematodes do reduce yields, resistance should confer a reproductive advantage and it should be possible to identify resistance in African cultivars.

Resistance to $M$. incognita in pearl millet should provide stability to pearl millet production and reduce nematode populations that can damage crops grown in rotation with pearl millet. One source of resistance to $M$. incognita has been identified to date (14). Identifying new sources of resistance will help in breeding new nematoderesistant cultivars. The objectives of this study were to (i) determine whether resistance to the southern root-knot nematode (M. incognita) exists in pearl millet cultivars from West and East Africa and (ii) determine whether heterogeneity for resistance exists within selected cultivars.

\section{MATERIALS AND METHODS}

General methods. $M$. incognita race 3 was cultured on tomato (Lycopersicon esculentum cv. Rutgers). Nematode eggs used for inoculum were extracted from tomato roots with $0.5 \% \mathrm{NaOCl}$ within $4 \mathrm{~h}$ of application (4). The soil used in the experiments was a loamy sand $(82 \%$ sand, $9 \%$ silt, $7 \%$ clay, $1 \%$ organic matter) that had been steam heated at $100^{\circ} \mathrm{C}$ for $6 \mathrm{~h}$. Treatments (pearl millet cultivar or selection) were completely randomized on two neighboring benches in a greenhouse where soil temperatures varied between 20 and $35^{\circ} \mathrm{C}$. Plants were fertilized with a slow-release formulation (14-14-14, N-P$\mathrm{K})$ and watered one to two times per day as needed. At the end of the experiments, the root systems were washed free of soil, patted dry, and weighed. Nematode eggs were extracted from the pearl millet roots by cutting the entire root system into approximately $5-\mathrm{cm}$ pieces, placing the pieces in a 1-liter flask, and agitating for 4 min in a $1 \% \mathrm{NaOCl}$ solution (4). Eggs were collected and rinsed with tap water on nested 150- and 25- $\mu \mathrm{m}$-pore sieves, and counted using a dissecting microscope.

In each experiment, pearl millet panicles were bagged to obtain selfed seed which was used in the subsequent experiment. $S_{1}$ seed harvested from experiment 1 was used to plant experiment 2 , and $S_{2}$ seed harvested from experiment 2 was used to plant experiment 3 .

Experiment 1. Seventeen pearl millet cultivars of diverse origin (Table 1) were evaluated in two trials to determine whether resistance to $M$. incognita existed in West and East African cultivars. The pearl millet evaluated in this study consisted of traditional, experimental, and improved cultivars that, together, are adapted to most of the growing zones in West and East Africa. The U.S. hybrid HGM-100 was included as a susceptible control. For each pearl millet cultivar, 10 $\mathrm{S}_{0}$ seed were planted in a $11-\mathrm{cm}$-diameter circle within a $23-\mathrm{cm}$-diameter pot containing 6 liters of soil. Seed were sown on 26 November 2002 (trial 1) and 13 March 2003 (trial 2). Plants were thinned to five per pot and inoculated with 10,000 eggs of M. incognita 28 days (trial 1) and 19 days (trial 2) after planting. Eggs were distributed in a shallow trench inside the planting circle and covered with soil. For each cul- 
tivar within a trial, there were eight replications (pots), each containing five plants. Nematode eggs were extracted from roots 71 and 67 days after inoculation in trial 1 and trial 2, respectively.

Experiment 2. Four cultivars (SoSatC88, Gwagwa, Zongo, and P3Kollo) were selected to determine whether heterogeneity for resistance to $M$. incognita could be identified within cultivars. These four cultivars were selected based upon their relative levels of resistance in experiment 1 , their diversity of origin and level of improvement (Table 1), their significance in African production settings, and available quantities of $S_{1}$ seed. $S_{1}$ progeny of 30 randomly selected $S_{0}$ plants from the four cultivars in experiment 1 were evaluated for nematode reproduction. Because of limited greenhouse space, plants of P3Kollo and Zongo were tested together (experiment 2a) and plants of Gwagwa and SoSat-C88 were tested together (experiment 2b). Each experiment included U.S. hybrids HGM-100 and TifGrain 102 as the susceptible and resistant controls, respectively. Two $S_{1}$ seed were planted in $10-\mathrm{cm}^{2}$ pots containing $700 \mathrm{~cm}^{3}$ of soil. Seed were sown on 28 October 2003 for P3Kollo and Zongo and on 24 February 2004 for Gwagwa and SoSat-C88 and thinned to one plant per pot after germination. Pots were inoculated with 8,200 eggs of $M$. incognita 28 and 23 days after planting for experiments $2 \mathrm{a}$ and $2 \mathrm{~b}$, respectively. The eggs were distributed between two holes (approximately $2 \mathrm{~cm}$ deep) at the base of the plant. For each experiment, there were five replicate pots per $S_{1}$ progeny selection. Nematode eggs were extracted from roots 84 and 90 days after inoculation in experiments $2 \mathrm{a}$ and $2 \mathrm{~b}$, respectively.

Experiment 3. The level of resistance to $M$. incognita was evaluated in progeny from 13 plants $\left(S_{1}\right)$ from each of the four cultivars to verify results obtained in experiment $2 . S_{2}$ progeny from 10 putatively resistant and 3 putatively susceptible $S_{1}$ plants within each cultivar were selected based upon relative eggs per gram of root and seed availability. A greater number of putatively resistant progeny was evaluated to identify false-resistant classifications and to advance resistant selections for future studies. The number of progeny advanced for each cultivar was limited in order to test all the selections in a single experiment. HGM-100 and TifGrain 102 were included as susceptible and resistant controls, respectively.

Two $\mathrm{S}_{2}$ seed were planted in $10-\mathrm{cm}^{2}$ pots containing $700 \mathrm{~cm}^{3}$ of soil. Seed were sown on 1 November 2004 and thinned to one plant per pot after germination. Pots were inoculated with 8,200 eggs of $M$. incognita 28 days after planting. The eggs were distributed between two holes (approximately $2 \mathrm{~cm}$ deep) at the base of the plant. For each experiment, there were five replicate pots per progeny selection. Nematode eggs were extracted from roots 85 days after inoculation.

Statistical analysis. Mixed model analysis of variance (PROC MIXED, v. 7; SAS Institute, Cary, NC) was used to analyze data from all three experiments. In the first experiment, cultivar was classified as a fixed effect and trial was classified as a random effect. Fisher's least significant difference (LSD) test was used to determine differences $(P \leq 0.05)$ among the cultivars. In the second and third experi-

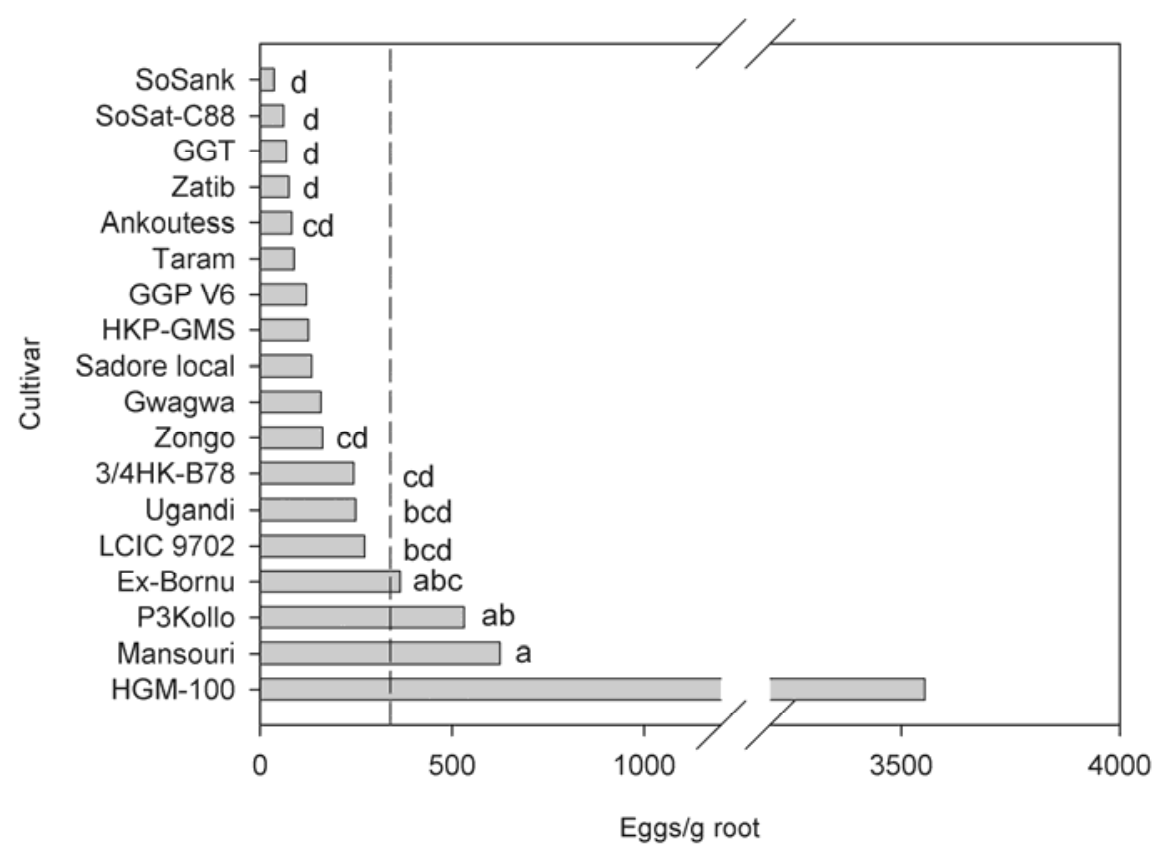

Fig. 1. Reproduction of Meloidogyne incognita race 3 on 17 pearl millet cultivars from West and East Africa. Data are the mean of two experiments. Each experiment contained eight replicate pots of each cultivar and five plants per pot. The dashed line indicates $10 \%$ of the level of reproduction of HGM100 (the susceptible control). HGM-100 had greater $(P \leq 0.05)$ nematode reproduction than all the African cultivars. Bars with the same letter are not different $(P \leq 0.05)$.

Table 1. Pearl millet cultivars from West and East Africa evaluated for resistance to Meloidogyne incognita race 3

\begin{tabular}{lll}
\hline Cultivar & Origin and type & \multicolumn{1}{c}{ Other information } \\
\hline SoSank & Niger improved & SoSat-C88 $\times$ Ankoutess derivative \\
SoSat-C88 & Mali improved & Souna $\times$ Sanio derivative \\
GGT & Niger experimental & Gros Grain Tardif-derivative of photoperiod-sensitive accession from Benin (IP 10437) \\
Zatib & Niger improved & Derivative of two local landraces \\
Ankoutess & Niger (north) local & $\ldots$ \\
Taram & Niger improved & Derivative of local from Tara, Niger \\
GGP V6 & Niger experimental & Gros Grain Précoce-derived from Iniari landraces from Togo \\
HKP GMS & Niger improved & Haïni Kiré Précoce-“shibra" removed through grid mass selection \\
Sadoré local & Niger (west) local & $\ldots$ \\
Gwagwa & Nigeria local & $\ldots$ \\
Zongo & Niger (east) local & $\ldots$ \\
3/4 HK-B78 & Niger experimental & Dwarf cultivar with Haïni Kiré parentage \\
Ugandi & Sudan improved & Composite from recurrent selection \\
LCIC 9702 & Nigeria improved & GB 8735 parentage \\
Ex-Bornu & Nigeria local & Recurrent selection from local landrace \\
P3Kollo & Niger improved & Derivative of two local landraces \\
Mansouri & Sudan improved & Mass selection from local landrace \\
HGM-100 & U.S. hybrid & Susceptible control \\
TifGrain 102 & U.S. hybrid & Resistant control \\
\hline
\end{tabular}


ment, the selections were classified as a fixed effect and Dunnett's test was used to determine which progeny selections were different from the susceptible control HGM-100. Differences among the cultivars in experiments $2 \mathrm{a}$ and $2 \mathrm{~b}$ also were determined by pooling the progeny data ( $n$ $=150$ for the African cultivars and $n=5$ for HGM-100 and TifGrain 102) and using Fisher's LSD test to separate the means for each experiment.

The number of genes conferring resistance in Zongo was estimated by $\chi^{2}$ tests using data from experiment 2 . These tests assumed that the Zongo $S_{0}$ population was in Hardy-Weinberg equilibrium, resistance was dominant, and allele frequencies were 0.5 . The $\chi^{2}$ values were calculated based upon the expected ratios of resistant (R) and susceptible (S) phenotypes in the $S_{1}$ progeny for one (5R:3S) or two (55R:9S) dominant genes conferring resistance.

Heritability of root-knot nematode reproduction (eggs per gram of root) was estimated by two methods using data pooled across the four cultivars selected. In order to correct for the differences in nematode reproduction in the two trials of experiment 2 , all data were standardized as the proportion of eggs produced on the HGM-100 control. Heritability by parentoffspring regression was calculated as $2 / 3 b$, where $b$ is the regression coefficient resulting from regression of $S_{2}$ progeny mean on $S_{1}$ parental value (13). In the second method, realized heritability $\left(h^{2}\right)$ was calculated as $h_{R}^{2}=\left(\bar{X}\right.$ high $\mathrm{S}_{2}-$ $\bar{X}$ low $\left.\mathrm{S}_{2}\right) /\left(\bar{X}\right.$ high $\mathrm{S}_{1}-\bar{X}$ low $\left.\mathrm{S}_{1}\right)$, where $\bar{X}$ high $\mathrm{S}_{\mathrm{n}}$ and $\bar{X}$ low $\mathrm{S}_{\mathrm{n}}$ are the means of the progeny lines selected for high and low nematode reproduction, respectively (3).

\section{RESULTS}

Experiment 1. When evaluated as bulked cultivars (five plants per pot), all African accessions had lower $(P<0.05)$ levels of $M$. incognita reproduction compared with the susceptible control HGM100 (Fig. 1). SoSank, SoSat-C88, GGT, and Zatib were more $(P<0.05)$ resistant than Mansouri, P3Kollo, and Ex-Bornu. Genotypes or cultivars are considered highly resistant if reproduction is $<10 \%$ that of the susceptible control and moderately resistant if reproduction is $>10 \%$ but statistically less than the susceptible control (5). Based on these criteria, Ex-Bornu, P3Kollo, and Mansouri appear to be moderately resistant, whereas the other cultivars are highly resistant to $M$. incognita.

Experiment 2. Data from experiments $2 \mathrm{a}$ and $2 \mathrm{~b}$ could not be compared directly because nematode reproduction differed in magnitude. Greater reproduction occurred in the test of P3Kollo and Zongo than in the test of Gwagwa and SoSat-C88. Therefore, reactions between pearl millet populations can be compared only relative to the HGM-100 and TifGrain 102 controls. In each cultivar, the progeny varied from

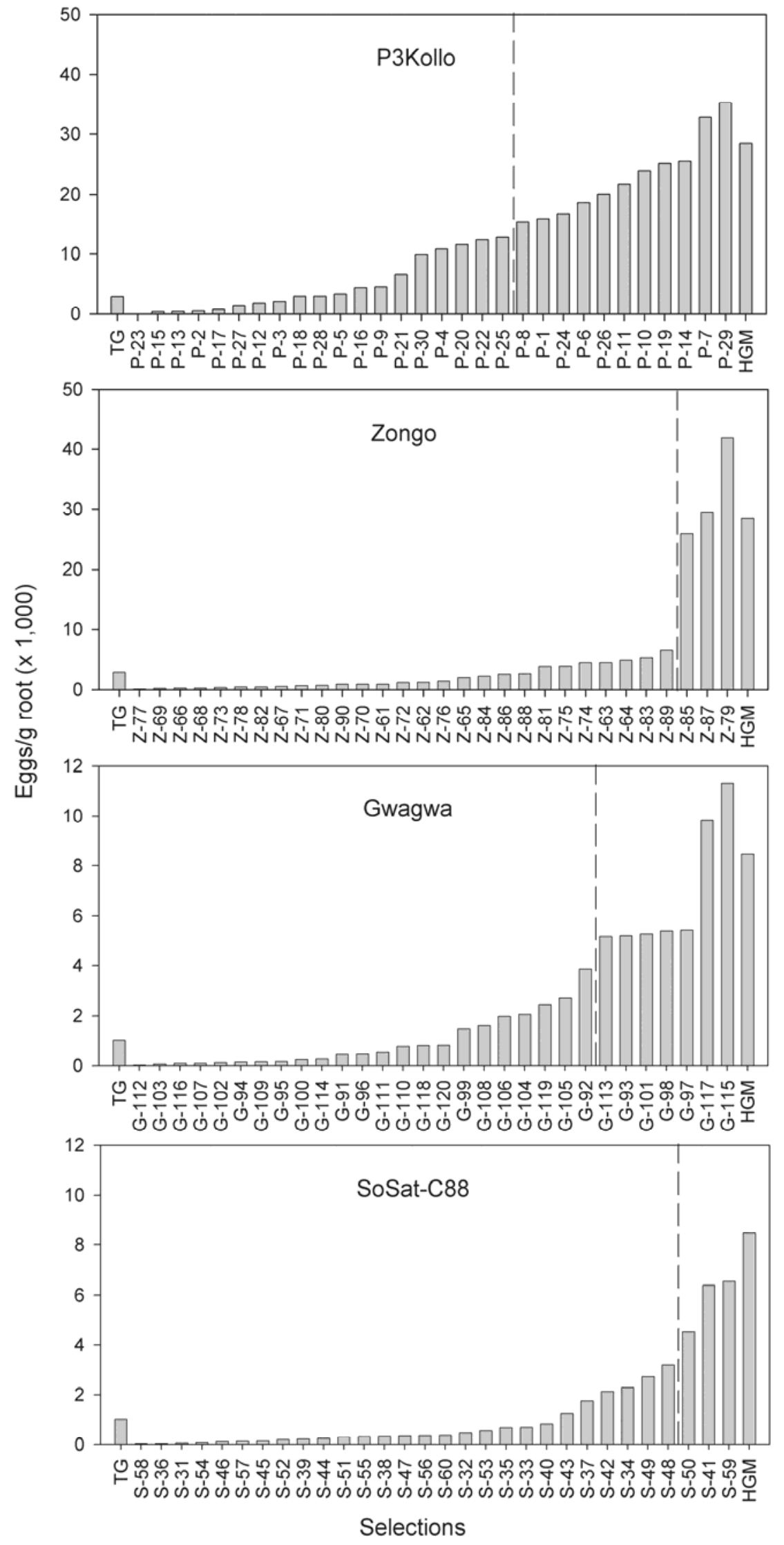

Fig. 2. Reproduction of Meloidogyne incognita race 3 on randomly selected $S_{1}$ progeny of four pearl millet cultivars from West Africa, evaluated in two greenhouse trials. P3Kollo and Zongo were grown in fall 2003, and Gwagwa and SoSat-C88 were grown in spring 2004. TifGrain 102 (TG) and HGM100 (HGM) are the resistant and susceptible controls, respectively. Selections to the left of the dotted line differ from HGM-100 $(P \leq 0.05)$. None of the resistant selections were more resistant than TifGrain 102. 
highly resistant $(<10 \%$ the reproduction on HGM-100) to susceptible (reproduction similar to HGM-100) (Fig. 2).

The distribution of nematode reproduction in $\mathrm{S}_{1}$ progeny varied among P3Kollo, Zongo, Gwagwa, and SoSat-C88 (Fig. 2). P3Kollo progeny exhibited a continuum of reproduction from low (resistant) to high (susceptible). Most of the Zongo progeny were highly resistant, and only a few progeny were susceptible. Averaged across progenies, nematode reproduction was greater $(P=0.0006)$ on P3Kollo $(11,449$ eggs/g of root) than on Zongo $(5,134$

Table 2. Reproduction of Meloidogyne incognita race 3 on $S_{1}$ and $S_{2}$ progeny of four pearl millet cultivars from West Africa evaluated in the greenhouse

\begin{tabular}{|c|c|c|c|c|c|}
\hline \multirow[b]{2}{*}{ Cultivar } & \multirow[b]{2}{*}{$\begin{array}{l}\text { Progeny } \\
\text { selection }\end{array}$} & \multicolumn{3}{|c|}{ Nematode reproduction ${ }^{a}$} & \multirow[b]{2}{*}{$\begin{array}{c}\mathbf{S}_{2} \\
\text { class }^{b}\end{array}$} \\
\hline & & $\begin{array}{c}\mathbf{S}_{1} \\
(\% \text { HGM-100) }\end{array}$ & $\begin{array}{c}\mathbf{S}_{2} \\
(\% \text { HGM-100) }\end{array}$ & $\begin{array}{c}\mathrm{S}_{2} \\
\text { (eggs/g of root) }\end{array}$ & \\
\hline HGM-100 & & & & 9,502 & \\
\hline P3Kollo & $\mathrm{P}-15$ & 0.9 & 0.4 & 43 & $\mathrm{R}$ \\
\hline P3Kollo & P-17 & 1.8 & 0.5 & 50 & $\mathrm{R}$ \\
\hline P3Kollo & $\mathrm{P}-2$ & 1.2 & 0.8 & 79 & $\mathrm{R}$ \\
\hline P3Kollo & P-18 & 7.5 & 1.0 & 95 & $\mathrm{R}$ \\
\hline P3Kollo & P-3 & 5.2 & 1.7 & 164 & $\mathrm{R}$ \\
\hline P3Kollo & P-23 & 0.3 & 1.9 & 185 & $\mathrm{R}$ \\
\hline P3Kollo & $\mathrm{P}-27$ & 3.5 & 6.6 & 625 & $\mathrm{R}$ \\
\hline P3Kollo & P-13 & 1.1 & 8.8 & 832 & $\mathrm{R}$ \\
\hline P3Kollo & P-14 & 64.4 & 12.1 & 1,153 & $\mathrm{R}$ \\
\hline P3Kollo & P-28 & 7.5 & 12.8 & 1,212 & $\mathrm{R}$ \\
\hline P3Kollo & P-7 & 82.6 & 51.0 & 4,868 & $\mathrm{R}$ \\
\hline P3Kollo & P-29 & 88.8 & 56.2 & 5,344 & $\mathrm{~S}$ \\
\hline P3Kollo & P-12 & 4.6 & 83.4 & 7,922 & $\mathrm{~S}$ \\
\hline Zongo & Z-69 & 0.5 & 0.1 & 12 & $\mathrm{R}$ \\
\hline Zongo & Z-68 & 0.7 & 0.2 & 21 & $\mathrm{R}$ \\
\hline Zongo & Z-82 & 1.2 & 0.5 & 52 & $\mathrm{R}$ \\
\hline Zongo & Z-66 & 0.6 & 0.6 & 57 & $\mathrm{R}$ \\
\hline Zongo & Z-77 & 0.3 & 0.9 & 88 & $\mathrm{R}$ \\
\hline Zongo & Z-80 & 1.9 & 1.0 & 99 & $\mathrm{R}$ \\
\hline Zongo & Z-78 & 1.1 & 1.8 & 174 & $\mathrm{R}$ \\
\hline Zongo & Z-73 & 0.7 & 2.3 & 215 & $\mathrm{R}$ \\
\hline Zongo & Z-90 & 2.3 & 3.0 & 280 & $\mathrm{R}$ \\
\hline Zongo & Z-67 & 1.4 & 48.5 & 5,756 & $\mathrm{~S}$ \\
\hline Zongo & Z-87 & 74.4 & 71.0 & 6,750 & $\mathrm{~S}$ \\
\hline Zongo & Z-85 & 65.4 & 72.1 & 6,853 & $\mathrm{~S}$ \\
\hline Zongo & $\mathrm{Z}-79$ & 105.6 & 118.0 & 11,215 & $\mathrm{~S}$ \\
\hline Gwagwa & G-102 & 1.6 & 0.3 & 27 & $\mathrm{R}$ \\
\hline Gwagwa & G-116 & 1.1 & 0.8 & 80 & $\mathrm{R}$ \\
\hline Gwagwa & G-103 & 0.9 & 1.8 & 172 & $\mathrm{R}$ \\
\hline Gwagwa & G-107 & 1.2 & 2.0 & 193 & $\mathrm{R}$ \\
\hline Gwagwa & G-117 & 116.2 & 7.4 & 700 & $\mathrm{R}$ \\
\hline Gwagwa & G-100 & 2.9 & 13.9 & 1,325 & $\mathrm{R}$ \\
\hline Gwagwa & G-114 & 3.3 & 17.1 & 1,626 & $\mathrm{R}$ \\
\hline Gwagwa & G-120 & 9.7 & 17.7 & 1,680 & $\mathrm{R}$ \\
\hline Gwagwa & G-113 & 61.1 & 22.9 & 2,174 & $\mathrm{R}$ \\
\hline Gwagwa & G-118 & 9.6 & 28.8 & 2,735 & $\mathrm{R}$ \\
\hline Gwagwa & G-94 & 1.8 & 31.4 & 2,982 & $\mathrm{R}$ \\
\hline Gwagwa & G-96 & 5.6 & 32.2 & 3,062 & $\mathrm{R}$ \\
\hline Gwagwa & G-115 & 107.0 & 188.0 & 17,866 & $\mathrm{~S}$ \\
\hline SoSat-C88 & S-57 & 1.7 & 0.4 & 34 & $\mathrm{R}$ \\
\hline SoSat-C88 & S-31 & 0.8 & 0.5 & 50 & $\mathrm{R}$ \\
\hline SoSat-C88 & S-39 & 2.8 & 1.2 & 111 & $\mathrm{R}$ \\
\hline SoSat-C88 & S-45 & 1.8 & 3.0 & 285 & $\mathrm{R}$ \\
\hline SoSat-C 88 & S-36 & 0.5 & 5.2 & 496 & $\mathrm{R}$ \\
\hline SoSat-C88 & S-58 & 0.5 & 6.8 & 641 & $\mathrm{R}$ \\
\hline SoSat-C88 & S-52 & 2.5 & 12.7 & 1,205 & $\mathrm{R}$ \\
\hline SoSat-C88 & S-46 & 1.5 & 17.3 & 1,645 & $\mathrm{R}$ \\
\hline SoSat-C88 & S-55 & 3.7 & 19.4 & 1,845 & $\mathrm{R}$ \\
\hline SoSat-C88 & S- 48 & 37.6 & 31.8 & 3,026 & $\mathrm{R}$ \\
\hline SoSat-C88 & S-51 & 3.5 & 71.6 & 6,800 & $\mathrm{~S}$ \\
\hline SoSat-C88 & S-59 & 77.4 & 145.0 & 13,775 & $\mathrm{~S}$ \\
\hline SoSat-C88 & $\mathrm{S}-50$ & 53.7 & 148.5 & 14,111 & $\mathrm{~S}$ \\
\hline TifGrain 102 & $\ldots$ & 12.1 & 7.0 & 665 & $\ldots$ \\
\hline $\operatorname{LSD}(P=0.05)^{\mathrm{c}}$ & $\ldots$ & $\ldots$ & $\ldots$ & 4,592 & $\ldots$ \\
\hline
\end{tabular}

${ }^{a}$ Data for selected $S_{1}$ and corresponding $S_{2}$ progenies are expressed relative to nematode reproduction on the susceptible hybrid HGM-100. $S_{1}$ progenies were evaluated in experiment 2 and $S_{2}$ progenies were evaluated in experiment 3. Hybrid TifGrain 102 was included as the resistant control in each evaluation. Data are the mean of five replications.

${ }^{\text {b }} S_{2}$ phenotype classification: $R=$ resistant $S_{2}$ progeny, $S=$ susceptible $S_{2}$ progeny. Susceptible phenotypes had nematode reproduction similar to or greater than $(P \leq 0.05)$ that of HGM-100.

${ }^{c}$ LSD $=$ least significant difference.

eggs/g of root). Gwagwa contained a greater number of susceptible genotypes than did SoSat-C88. Averaged across progenies, nematode reproduction was greater $(P=0.02)$ on Gwagwa $(2,246$ egg/g of root) than on SoSat-C88 (1,252 eggs/g of root). Averaged across progenies, egg production on the four cultivars was less $(P \leq 0.001)$ than on HGM-100, but was not different from TifGrain 102.

Discreet resistant and susceptible phenotypes (i.e., no intermediate phenotypes) were identified only in $S_{1}$ progeny of Zongo (Fig. 2). Reproduction on Z-85, -87, and -79 were different $(P<0.05)$ from TifGrain 102, and reproduction on the remaining progeny were different from HGM 100. Distinct phenotypic classes of $S_{1}$ progeny of the other cultivars were less clear. P3Kollo progenies with reproduction greater than P-25 and less than P-11 were classified as susceptible because they did not differ from HGM-100, but they also were not different from the resistant control TifGrain 102. Gwagwa progeny G-113 and SoSat-C88 progeny S-50 did not differ $(P<0.05)$ from either HGM 100 or TifGrain 102.

The discreet phenotypic classes identified in Zongo allowed an estimate of the number of genes conferring resistance by $\chi^{2}$ tests. Within the limits of the assumptions identified earlier, the 27R:3S phenotypic segregation in Zongo was consistent with the segregation of two dominant genes $\left(\chi^{2}=0.399,0.50<P<0.75\right)$. Estimates for the other cultivars tend to support a one- or two-gene hypothesis; however, phenotypic classes defined by comparison to the resistant and susceptible controls were overlapping. Estimates for P3Kollo are particularly problematic, given the distribution of nematode reproduction for the progeny. This distribution is likely the result of multiple genes with minor effects on nematode reproduction, or major genes that are associated with large environmental variances.

Experiment 3. Nematode reproduction on the $S_{2}$ progeny in experiment 3 tended to confirm the results from the $S_{1}$ progeny in experiment 2. With a few exceptions, progeny rated as resistant or susceptible in experiment 2 were confirmed as such in experiment 3 (Table 2). Among the 52 progeny lines tested, 7 (P-7, P-12, P-14, Z67, G-113, G-117, and S-51) exhibited contradictory reactions between experiments 2 and 3. Most of the contradictory results could be explained by segregation within the $S_{1}$ progeny for resistance to $M$. incognita. Although the average egg production on P-14, G-113, and G-117 was relatively high in the $S_{1}$ (Fig. 2; Table 2), the plant selected for advance to the $S_{2}$ exhibited a resistant reaction (i.e., low egg production). In contrast, the average egg production on $\mathrm{P}-12$ and Z-67 was relatively low in the $S_{1}$, but the plant selected for advance to the $S_{2}$ exhibited a suscepti- 
ble reaction (i.e., high egg production). The reason for the contradictory results in the remaining two progeny lines was not apparent. Average nematode reproduction was relatively high on P-7 $\mathrm{S}_{1}$ and $\mathrm{S}_{2}$ (Table 1). However, because egg production on $\mathrm{P}$ $7 \mathrm{~S}_{2}$ was less than on HGM-100 $(P<$ $0.05)$, it was classified as resistant. Within SoSat-C88, the contradictory reactions for S-51 (Table 2) could not be explained by examining the individual plant data from experiment 2. The discrepancy with S-51 may have been due to environmental conditions in the pots that inhibited nematode survival and root infection, or to misidentification of the seed source.

Heritability of nematode reproduction (standardized as the ratio of the value to HGM-100) as determined by regression of $S_{2}$ progeny means on $S_{1}$ parent means was calculated to be 0.54 . Realized heritability determined by comparison of lines selected for either high or low reproduction was calculated to be 0.87 .

\section{DISCUSSION}

Each of the 17 African pearl millet cultivars was considered to be more resistant than the susceptible control HGM-100 when evaluated as bulk cultivars in experiment 1. Among the African cultivars, there was a range of responses from highly to moderately resistant, but no pattern was discerned between resistance and country of origin. Some relationships exist among some of these cultivars. SoSank was derived from a cross between SoSat-C88 and Ankoutess. Haïni Kiré was the source of HKP-GMS and was a parent of $3 / 4 \mathrm{HK}$ B78. Related cultivars did not differ in nematode reproduction when evaluated in $\mathrm{S}_{0}$ bulks.

A prior study of the diversity and relationships among several African pearl millet lines based upon morphological traits, downy mildew resistance, and yield and yield components found that pearl millet cultivars from Niger clustered together, whereas Iniari, Mansouri, and Ugandi formed a different cluster (10). In our studies, P3Kollo from Niger was more susceptible than most of the other pearl millet from Niger, while Ugandi was more resistant than Mansouri. Neither geographic origin nor relationships determined from the prior study (10) were a good predictor of resistance in our limited samples.

It was possible to select several unrelated cultivars differing in geographic region of importance that also showed a range of nematode reproduction. SoSatC88 is a recent improved cultivar that is widely grown in Mali, Burkina Faso, Niger, and Nigeria. Gwagwa is a local cultivar grown in Nigeria. Zongo is a local cultivar grown in east Niger. P3Kollo is an older improved cultivar developed by International Crops Research Institute for the Semi-Arid Tropics (ICRISAT) that has been grown in Niger.
The data from experiment 2 indicate that the bulk analysis of cultivars in experiment 1 gave a reasonable assessment of the relative level of resistance within cultivars. Zongo was confirmed to be more resistant than P3Kollo, and SoSat-C88 was confirmed to be more resistant than Gwagwa. More detailed evaluation of individual plant selections clearly demonstrated that heterogeneity for resistance to root-knot nematode existed within the four diverse cultivars. Although only four cultivars were chosen for the more detailed evaluation in experiments 2 and 3, they represented the range of observed resistance responses in experiment 1 . It is likely that further analysis would reveal similar segregation of resistance and susceptibility among progeny of the other cultivars. The phenotypic class ratios observed in Zongo progeny suggests two dominant genes for resistance. The distributions observed in the other three cultivars require additional research to determine inheritance of resistance.

African pearl millet consists of openpollinated cultivars that are genetically heterogeneous; therefore, allele frequencies are responsive to selection pressure. Previously evaluated landraces of pearl millet from Burkina Faso were heterogeneous for resistance to foliar diseases (16,17). Resistance to leaf blight (caused by Pyricularia grisea) was much more common than resistance to rust (caused by Puccinia substriata var. indica). Those data suggest that resistance to leaf blight confers some reproductive advantage and is maintained in the populations, whereas little selection pressure exists to maintain rust resistance in the African production setting. Although the importance of both diseases frequently is discounted in West African production settings (9), leaf blight is very common in West Africa, whereas rust is rarely observed (15). Resistance to $M$. incognita was readily identified in the four West African cultivars evaluated, leading us to hypothesize that this nematode exerts a significant selection pressure on pearl millet in West Africa. This scenario could have implications in production of pearl millet as well as in crops grown in rotation or in intercropping systems.

All pearl millet currently grown in Africa consists of open-pollinated cultivars, but research efforts are increasingly working toward the goal of hybrid production (1). When homogeneous hybrid cultivars are available, nematode resistance will be a valuable contribution to yield stability. If any of these pearl millet cultivars are to be used as sources of nematode resistance in the United States or West Africa, it will be necessary to identify specific resistant progeny selections as parents for breeding or hybrid production. Heritability estimates were moderate to high, indicating that data from these controlled studies are a good predictor of progeny performance, and good progress is expected in selecting for resistance to $M$. incognita.

\section{ACKNOWLEDGMENTS}

Cooperative investigation of the USDA-ARS and the University of Georgia College of Agricultural and Environmental Sciences, with support from the International Sorghum and Millet CRSP. We thank O. Botorou, I. Angarawai, D. Hess, and G. Omanya for seed of cultivars used in these studies; and W. Wilson, T. Perla, and M. Purvis for technical assistance.

\section{LITERATURE CITED}

1. Angarawai I. I., Wilson, J. Ndahi, W. B., and Turaki, Z. G. S. 2004. Enhancing resourcepoor farmers productivity by pearl millet hybrid (sic). Pages 60-61 in: Proc. Millet and Sorghum-Based Syst. in West Africa: Current Knowledge and Enhancing Linkages to Improve Food Security. McKnight Foundation Collaborative Crop Research Foundation, Niamey, Niger.

2. Egunjobi, O. A. 1985. The International Meloidogyne Project in region IV: Current status, progress and future outlook, Pages 353360 in: An Advanced Treatise on Meloidogyne. Vol. I. Biology and Control. J. N. Sasser and C. C. Carter, eds. North Carolina University Graphics, Raleigh, NC.

3. Guthrie, D. A., Smith, E. L., and McNew, R. W. 1984. Selection for high and low grain protein in six winter wheat crosses. Crop Sci. 24:1097-1100.

4. Hussey, R. S., and Barker, K. R. 1973. A comparison of methods of collecting inocula for Meloidogyne spp., including a new technique. Plant Dis. Rep. 57:1025-1028.

5. Hussey, R. S., and Janssen, G. J. W. 2002 Root-knot nematodes: Meloidogyne species. In: Plant Resistance to Parasitic Nematodes. J. L. Starr, R. Cook, and J. Bridge, eds. CABI Publishing, Egham, UK.

6. Johnson, A. W., and Burton, G. W. 1977. Influence of nematicides on nematodes and yield of sorghum-sudangrass hybrids and millets. Plant Dis. Rep. 61:1013-1017.

7. Johnson, A. W., Burton, G. W., and Wright, W. C. 1977. Reactions of sorghum-sudangrass hybrids and pearl millet to three species of Meloidogyne. J. Nematol. 9:352-353.

8. Johnson, A. W., Hanna, W. W., and Dowler, C. C. 1995. Effects of irrigation, nitrogen, and a nematicide on pearl millet. J. Nematol. 27(4S):571-574.

9. Marley, P. S., Diourté, M., Neya, A., Nutsugah, S. K., Sérémé, P., Katilé, S. O., Hess, D. E. Mbaye, D. F., and Ngoko, Z. 2002. Sorghum and pearl millet diseases in West and Central Africa. Pages 419-425 in: Sorghum and Millets Diseases. J. F. Leslie, ed. Iowa State Press, Ames.

10. Ouendeba, B., Ejete, G., Hanna, W. W., and Kumar, A. K. 1995. Diversity among African pearl millet landrace populations. Crop Sci. 35:919-924.

11. Sasser, J. N., and Carter, C. C. 1982. Root-knot nematodes (Meloidogyne spp.): Identification, morphological and physiological variation, host range, ecology, and control. In: Nematology in the Southern Region of the United States. R. D. Riggs, ed. South. Coop. Ser. Bull 276:21-32.

12. Sasser, J. N., and Freckman, D. W. 1987. A world perspective on nematology: The role of the Society. Pages 7-14 in: Vistas on Nematology. J. A. Veech and D. W. Dickson, eds. Society of Nematologists, Hyattsville, MD.

13. Smith, J. D., and Kinman, M. L. 1965. The use of parent-offspring regression as an estimator of heritability. Crop Sci. 5:595-596.

14. Timper, P., Wilson, J. P., Johnson, A. W., and 
Hanna, W. W. 2002. Evaluation of pearl millet grain hybrids for resistance to Meloidogyne spp. and leaf blight caused by Pyricularia grisea. Plant Dis. 86:909-914.

15. Werder, J., and Manzo, S. K. 1992. Pearl millet diseases in western Africa. Pages 109-114 in: Sorghum and Millets Diseases: A Second World Review. W. A. J. de Milliano, R. A.
Frederiksen, and G. D. Bengston, eds. ICRISAT, Patencheru, India.

16. Wilson, J. P., Burton, G. W., Wells, H. D., Zongo, J. D., and Dicko, I. O. 1989. Leaf spot, rust, and smut resistance in pearl millet landraces from central Burkina Faso. Plant Dis. 73:345-349.

17. Wilson, J. P., Burton, G. W., Zongo, J. D., and
Dicko, I. O. 1991. Disease resistance and morphologic traits of pearl millet landraces from south Burkina Faso. Crop Sci. 31:641-645.

18. Wilson, J. P., Hess, D. E., and Hanna, W. W. 2000. Resistance to Striga hermonthica in wild accessions of the primary gene pool of Pennisetum glaucum. Phytopathology 90 1169-1172. 